\title{
Publisher Correction: Bisphosphonate-based surface biofunctionalization improves titanium biocompatibility
}

\section{Carolina Simão Albano ${ }^{1,2}$ - Anderson Moreira Gomes ${ }^{1} \cdot$ Geórgia da Silva Feltran ${ }^{1}$. \\ Célio Junior da Costa Fernandes ${ }^{1} \cdot$ Luciana Daniele Trino $^{2} \cdot$ Willian Fernando Zambuzzi $^{1,3}$. Paulo Noronha Lisboa-Filho ${ }^{2}$}

Published online: 27 November 2020

(c) Springer Science+Business Media, LLC, part of Springer Nature 2020

Correction to: Journal of Materials Science: Materials in Medicine https://doi.org/10.1007/s10856-020-06437-y

The original version of this article unfortunately contained a mistake. The graphical abstract was missing. It is given below. The original article has been corrected.

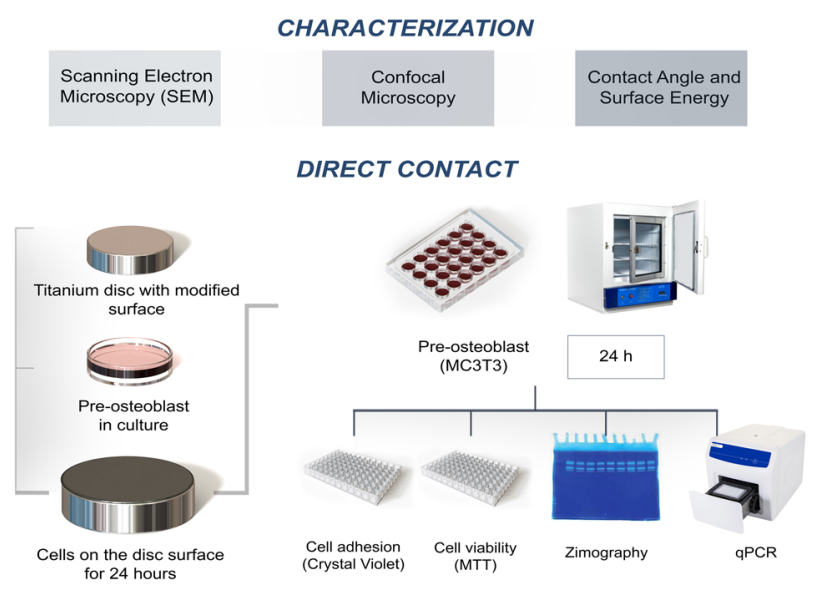

The original article can be found online at https://doi.org/10.1007/ s10856-020-06437-y.

Paulo Noronha Lisboa-Filho

paulo.lisboa@unesp.br

1 Department of Chemistry and Biochemistry, Institute of Biosciences of Botucatu, UNESP_São Paulo State University, Botucatu, Brazil
2 Department of Physics, UNESP — São Paulo State University, School of Sciences, Bauru, Brazil

3 Electron Microscopy Center, Institute of Biosciences of Botucatu, UNESP-São Paulo State University, Botucatu, Brazil 